\title{
CONTRIBUIÇÃO GEOMORFOLÓGICA AO ESTUDO DE ESCARPAS DA SERRA DO MAR
}

\author{
Olga CRUZ
}

\begin{abstract}
RESUMO
Autores têm-se referido à definição geomorfológica de escarpa, ou vertente escarpada, sem levar em conta as características topomorfológicas de comprimento, declividade e amplitude topográfica, básicas para o entendimento de sua evolução. No litoral norte do Estado de São Paulo, a serra do Mar, caracterizada por um conjunto de escarpas que marcam a borda oriental dos terrenos pré-cambrianos do Planalto Atlântico, apresenta dois compartimentos distintos. O primeiro, a montante, possui vertentes escarpadas, com segmentos retilíneos alongados e declivosos, entalhados por vales e anfiteatros de fortes amplitudes topográficas. Seu recuo faz-se paralelo, guiado por linhas litotectônicas de fraqueza, ou em alvéolos; processos de alteração e pedogênese produzem materiais levados para jusante por movimentos de massa em prancha ou por coluviação, preferencialmente durante episódios pluviais intensos. Num segundo compartimento, a jusante, nas médias e baixas encostas, as vertentes escarpadas são degradadas ou rebaixadas em diferentes níveis topográficos, que se desenvolvem sobre esporões secundários, rampas erosivas e coluviais, morros residuais e alvéolos, governados pelo traçado estrutural. Mamelonizadas por processos de intemperismo e pedogênese, escoamento pluvial superficial, fluxos internos e freáticos, estas formas sofrem ainda movimentos de massa, principalmente rotacionais; rampas coluviais e taludes de detritos formam por entre os esporões e morros rebaixados. Foram observadas relações estreitas entre os mapeamentos de declividades, cicatrizes de escorregamentos e isopletas. Nas vizinhanças de Caraguatatuba, duas áreas com grande ocorrência de cicatrizes apresentaram isopletas acima de 30 , coincidindo com as vertentes de grande comprimento e alta declividade nas zonas de maiores amplitudes topográficas.
\end{abstract}

\section{ABSTRACT}

Current definitions of scarps do not usually take into account topomorphological features of length, slope and local relief, which are basic to an understanding of their evolution. The northern sector of the coast of the state of São Paulo presents a set of scarps in Precambrian rocks, bounding the Atlantic Plateau to the interior. Two compartments can be discerned. The upper one has scarps with extensive straight and sloping segments, cut by valleys and amphitheaters of strong relief. The retreat of such scarps may proceed parallel to the front, under the control of lito-tectonic features, or transversely forming "alveoli" (small basins). Processes of weathering and pedogenesis yield materials that are moved downslope by mass movements and colluviation, mainly during intense pluvial episodes. On the lower compartment, on the middle and low slopes, scarps are degraded or worn down, resulting in topographic levels over secondary spurs, erosive and colluvial ramps, residual hills and "alveoli", under structural control. They are modelled into convex forms by weathering and pedogenesis, by overland and subsurface flows and also by mass movements, more frequently slump slides; colluvial ramps and debris talus occur among the spurs and residual hills. Maps of slope, landslide scars and isopleths show close relationship among themselves. In the vicinity of Caraguatatuba, two areas with a high incidence of scars present isopleths above 30 coinciding with long and steep slopes in the area of strongest relief.

\section{ESCARPAS, REVISÃO BIBLIOGRÁFICA}

É vaga a conceituação geomorfológica de vertente escarpada ou escarpa; tem sido pouco discutida e é na verdade difícil distingüi-la, a não ser a partir de índices ligados ao seu comprimento, declividade e amplitudes topográficas: segmentos retilíneos de vertentes comuns, não relacionadas a maiores amplitudes topográficas e altas declividades, não poderiam ser considerados vertentes escarpadas, ou melhor, escarpas.

Muitos autores, porém, não consideram tais índices ao definir escarpa. Para FAIRBRIDGE (1968), escarpa é a abreviação de escarpamento, um termo empregado desde Hutton e Playfair, e significa um abrupto em relevo, uma falésia ou uma "cuesta”. QUINN (1968) tam- 
bém descreve a escarpa ou escarpamento como penhasco, falésia ou face rochosa de grande comprimento, de origem erosiva ou estrutural. RUHE (1975) define-a como vertente de alta declividade que difere em gradiente de outras vertentes a montante e a jusante. Para BAULIG (1956), escarpa ou escarpamento é a borda de planalto mais ou menos dissecada, festonada, desgastada, com partes avançadas salientes em esporões, às vezes com morros fronteiros testemunhos. Refere-se também às escarpas de falha que, ao serem entalhadas por vales profundos em $\mathrm{V}$, decompõem-se em facetas trapezoidais e triangulares; uma vez erodidas, poderão ser substituídas por escarpas de linha de falha resseqüentes ou obseqüentes. Segundo LOCZI \& LADEIRA (1981), as escarpas de falha também podem ser de origem mista, geradas pela combinação da ação tectônica e erosão seletiva, enquanto as de linha de falha, de diversas categorias de acordo com o estágio de sua evolução, representam um relevo devido à erosão diferencial.

Foi, porém, em 1924 que PENCK (1953), representante da escola mobilista, ao realizar sua pesquisa sobre movimentos crustais e suas relações com as formas de relevo, se tornou o primeiro a procurar explicar a gênese das escarpas. Demonstrou especial interesse pelas variações da velocidade no aprofundamento dos talvegues, através da evolução de perfis de vertente, evolução esta que acabaria por resultar no "wearing back" ou recuo paralelo, chamado "recuo penckiano" por C.A.M. KING (1976), ao contrário do "wearing down" ou recuo por rebaixamento proposto por W.M. Davis. Baseado nas idéias de Penck, L.C. KING (1962) estabeleceu o raciocínio de que, em terras tropicais áridas, semi-áridas e em savanas, após levantamento isostático e aprofundamento da drenagem, as vertentes evoluiriam a partir de pediplanação, em escarpas com recuo paralelo. Manteriam então um ângulo de declividade constante, o "Knick" $\left(15-30^{\circ}\right)$, dependendo das forças a agir sobre elas, ajudadas pela resistência e a estruturação do substrato rochoso.

BIROT (1955) afirmava ser a história do relevo no globo dirigida pelo antagonismo tectônica-erosão, isto é, pela ação antagônica dos processos endogenéticos e exogenéticos; as mudanças climáticas não introduziriam senão variantes neste tema fundamental. De fato, SCHUMM \& CHORLEY (1966), ao pesquisarem sobre o recuo de escarpas no planalto do Colorado, chegaram à conclusão de que a interpretação de tais formas não dependia necessariamente de condições climáticas anteriores, mas sim do ritmo e velocidade de atuação de um complexo de processos erosivos atuais. Estes estariam ligados ao intem- perismo e queda de blocos rochosos, por sua vez conectados à natureza e à estruturação das rochas. Para isto, os autores levaram em consideração porosidade, orientação e espaçamento das juntas, planos de contato de rochas diferenciadas, seu mergulho e direção e, por fim, a ocorrência de afloramentos rochosos nas altas escarpas. $\mathrm{O}$ ângulo crítico de estabilidade em rochas de coesão efetiva seria de $90^{\circ}$; já em paredes com fortes e variadas ocorrências de juntas, este ângulo se apresentaria diversificado, uma vez que essa coesão efetiva se torna reduzida pelos ataques do intemperismo. No caso de a parte superior da escarpa oferecer maior resistência, por ser menos atingida por juntas, seu recuo seria mais lento, mesmo em presença de solapamento basal.

CHORLEY et al. (1984) novamente afirmaram ser o escarpamento uma linha de escarpas, formada por erosão e/ou falhamentos controlados por variações litológicas. Para os autores, a manutenção da forma escarpada de uma vertente só pode acontecer sob a proteção de cornija rochosa, ou pelo controle de suas altas declividades por sistemas de fraturas. Se forem compostas por material homogêneo ou originadas por falhamento muito recente, ou então por incisão fluvial, assumirão rapidamente a forma de vertentes comuns.

YOUNG (1972), conceituando "cliff" e "free face" como a parte mais abrupta de uma vertente, formada por rocha nua, coloca o problema do ataque por intemperismo a montante e da acumulação de detritos a jusante. Estes detritos tornam-se, a partir dos planos de juntas, novamente vulneráveis aos mesmos processos que rompem a coesão interna da rocha e solapam a sua base. O solapamento pode levar à ocorrência de movimentos rotacionais e a outros tipos de movimentos de massa. Tais fatos poderiam ser lembrados no caso de recuo paralelo das paredes escarpadas de grandes ravinas, uma vez atingido o lençol freático pelo aprofundamento de seus talvegues.

FANIRAM \& JEJE (1983) referem-se à ocorrência, em áreas tropicais úmidas, de escarpas de origem erosiva e de morfologia complexa que separam superfícies de erosão de diferentes idades, compostas por diversos níveis topográficos. Descrevem seu recuo paralelo e sua dissecação fluvial em gargantas profundas, sob controle de processos estruturais, intemperismo, escoamento pluvial e movimentos de massa. Dados de FREISE (1932, apud YOUNG, op. cit.) demonstram que o recuo é mais rápido em escarpas granítico-gnáissicas sob floresta e intenso intemperismo de áreas tropicais úmidas, como no Rio de Janeiro, onde se observa um recuo de 2 a $20 \mathrm{~mm}$ por ano. AB'SABER (1962), AB'SA- 
BER \& BIGARELLA (1961) e BIGARELLA et al. (1961), entre outros, têm-se referido às interpretações dos níveis existentes entre os blocos e as cristas da zona pré-serra do Mar. BIGARELLA (1978) faz uma súmula das fases de pedimentação que elaboraram seus compartimentos intermontanos e frontais e ALMEIDA (1953), dentre muitos, manifesta-se de acordo com a tectônica deformadora do relevo da serra do Mar, levando em conta o seu caráter de escarpamento erosivo.

\section{EVOLUÇÃO DE ESCARPAS COSTEIRAS DA SERRA DO MAR (COSTA N-NE DO ESTADO DE SÃO PAULO)}

As escarpas costeiras tropicais úmidas da serra do Mar, no denominado litoral norte do Estado de São Paulo, são compostas por enorme quantidade de vertentes alongadas, na sua maioria escarpadas, com fortes amplitudes topográficas entre os topos e o fundo dos vales. Talhadas em terrenos proterozóicos e arqueanos do Complexo Costeiro, relacionam-se a uma compartimentação topomorfológica nítida (CRUZ, 1986).

A montante, as altas vertentes escarpadas oferecem segmentos retilíneos longos e declivosos, com afloramentos rochosos e grandes amplitudes topográficas, criadas pelo entalhamento da drenagem fluvial. Esporões salientes com flancos escarpados, topos em crista ou, raramente, em pequenos patamares, rodeiam amplos anfiteatros de erosão nas cabeceiras, como alvéolos embutidos e suspensos. Desenvolve-se não somente um recuo paralelo ao alinhamento geral das escarpas e à faixa litorânea, mas também um recuo perpendicular, com a formação cada vez mais a montante de novos e pequenos alvéolos, às vezes entulhados por taludes de detritos, nas zonas sob maior influência litotectônica. $\mathrm{O}$ vale do rio Santo Antônio (fig. 1) é o exemplo típico dessa seqüência de alvéolos, o mais interno e mais recente, a montante, aberto em função do falhamento SW-NE Bertioga-Caraguatatuba (IPT, 1977 e 1981 e HASUI, 1982).

A jusante, porém, as escarpas apresentamse degradadas, com relevo onde se misturam freqüentemente baixas e altas declividades. Às vezes ficam reduzidas a segmentos retilíneos de vertentes comuns em variados ângulos de inclinação, formando patamares em rampas com topos aplainados e maior espessura do material de alteração. Tais aplainamentos, desenvolvidos por processos geomórficos sob influências litotectônicas, representam médios e baixos níveis topográficos, por vezes correlacionados a superfícies de aplainamento (AB'SABER, 1962). Morrotes altamente retocados por processos de conve- xização-mamelonização, por intemperismo e escoamento pluvial (CRUZ, 1982), ocorrem alternados a rampas de desgaste ou a setores côncavos, resultantes da acumulação de colúvios e de depósitos piemônticos em taludes detríticos. São também característicos das baixas encostas os alvéolos mais antigos, já alargados, delimitados por esporões rebaixados, dispostos em pinça (ALMEIDA, 1953). À medida que se alargam, evoluem, esvaziam e evacuam os detritos para o mar. Finalmente abrem-se para formar as planícies costeiras, com deposições marinhas antigas, recentes e atuais. Os depósitos piemônticos, por sua vez, são o produto do recuo das escarpas e a ele são proporcionais. Não coesos, são virtualmente atingidos por "piping" de águas subsuperficiais e freáticas e por novas levas de movimentos de massa, as quais freqüentemente neles se encaixam em camadas sucessivas de corridas de lama e blocos, destruindo-os parcialmente. Por isto, são em geral lobados, dissecados e heterogêneos quanto à sua composição, vinculados não somente a uma fase temporal de formação, mas a um complexo depósito de diversas épocas, incluindo a atual.

$\mathrm{O}$ alvéolo maior de jusante, no vale do rio Santo Antônio (fig. 1) é fechado pelos esporões secundários do pico do Tinga e do morro do Benfica, influenciados pela linha de fraturamento WSW-ENE de Caraguatatuba-Camburu. No vale do rio do Pau d'Alho e de seus afluentes (fig. 3 ), os alvéolos de jusante são menores, alguns cheios de acumulações detríticas e delimitados pelos morros rebaixados e mamelonados.

Tal compartimentação leva ao entendimento da evolução geomorfológica da serra do Mar no setor estudado, uma vez que as formas, segundo SWAN (1972), estão sempre relacionadas às etapas de sua evolução.

\section{OCORRÊNCIA DE MOVIMENTOS DE MASSA NA EVOLUÇÃO DAS ESCARPAS COSTEIRAS DA SERRA DO MAR EM CARAGUATATUBA}

Baseado no princípio do Uniformitarismo, SHARPE (1938) pensava ser difícil aceitar processos catastróficos como fatores importantes na denudação terrestre, como também achava detestável atribuir um grande peso aos movimentos imperceptíveis e lentos da reptação de solo e rocha. Segundo ele, porém, estudos de campo em áreas selecionadas convencem, mesmo o mais cético observador, de que os movimentos de massa podem ser reconhecidos como dos mais importantes processos geomórficos. Segundo ZARUBA \& MENCL (1969), quando a estabi- 


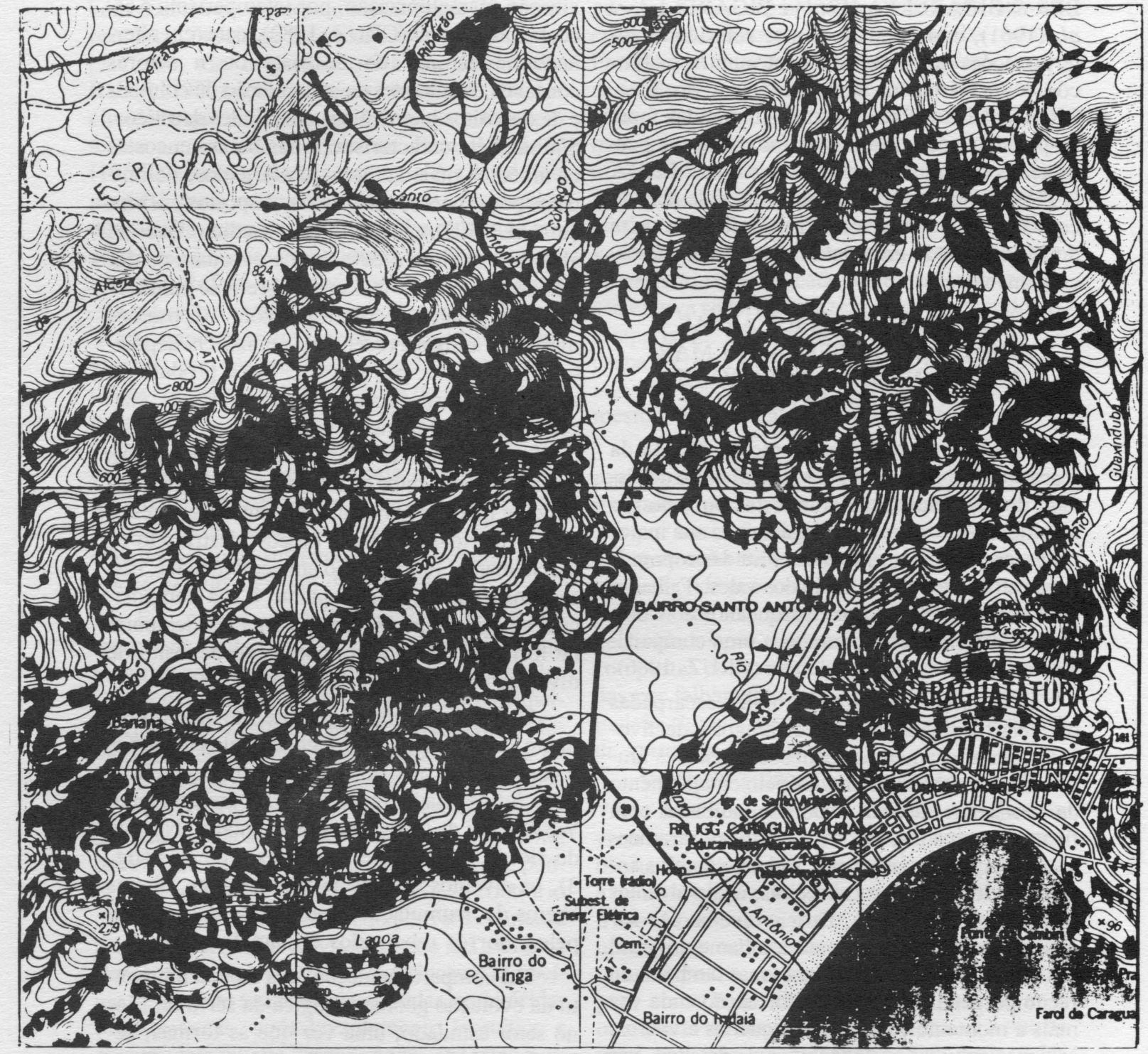

Fig. 1

Equidistāncia das Curvas de Nivel: $20 \mathrm{~m}$

FONTE : Folha Topográfica de Caraguatatuba-Estado de Szo Paulo

Escala: $1: 50.000-1 B G E-1972$ 


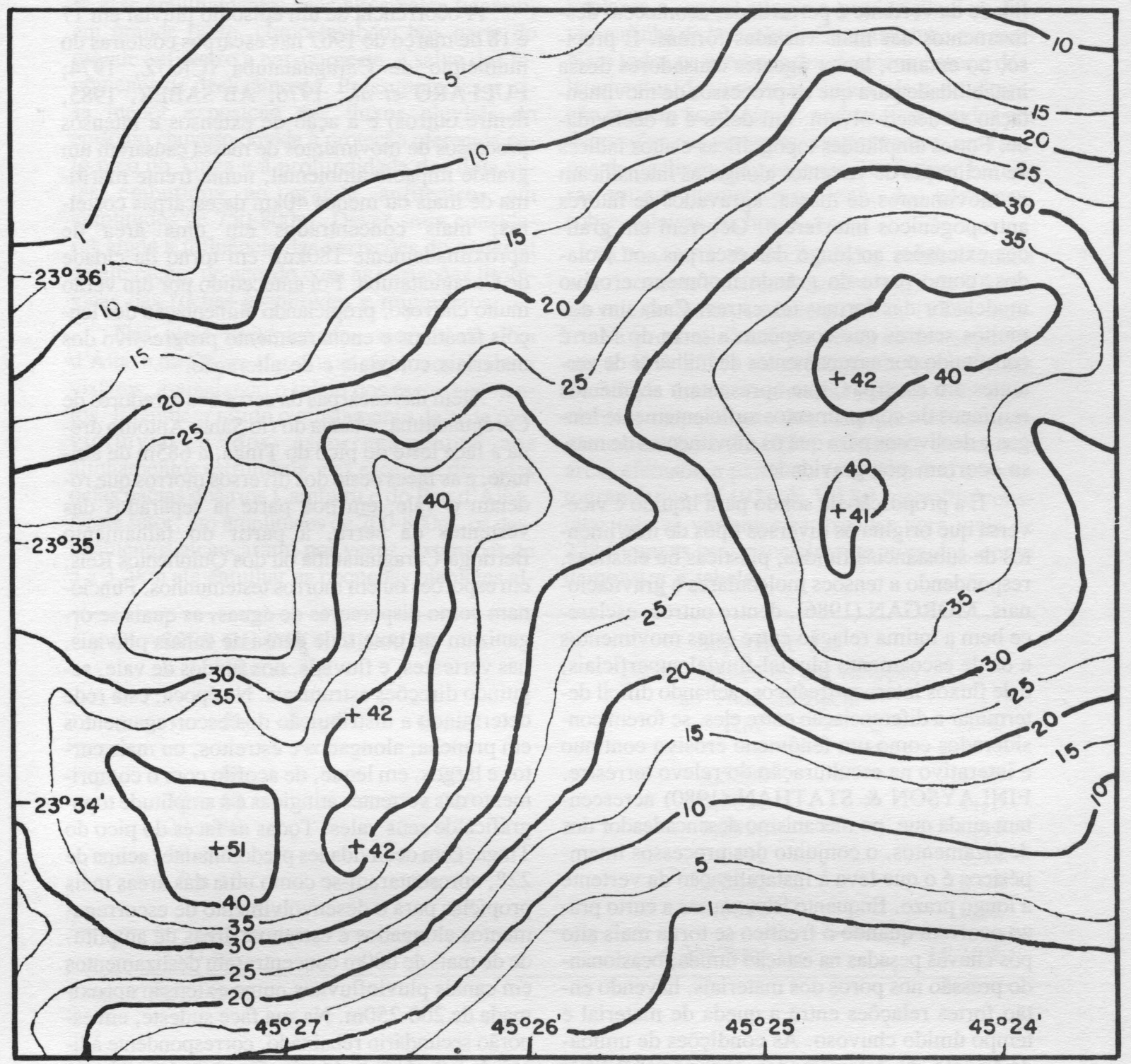

Fig. 2

Equidistancia das Isopletas: valor 5 
lidade da vertente é perturbada, acontecem deslizamentos das mais variadas formas. É preciso, no entanto, haver agentes causadores dessa instabilidade para que os processos de movimentação se desenvolvam: um deles é a declividade. Fortes amplitudes topográficas e altos índices de inclinação de vertentes alongadas intensificam os movimentos de massa, agravados se fatores antropogênicos interferem. Ocorrem em grandes extensões ao longo das escarpas, ou isolados, como parte do grande fenômeno erosivo modelador das formas terrestres. Cada um dos muitos setores que compõem a serra do Mar é constituído por agrupamentos de milhares de vertentes em escarpas, que apresentam segmentos retilíneos de comprimentos suficientemente longos e declivosos para que os movimentos de massa ocorram por gravidade.

É a proporção de sólido para líquido e viceversa que origina os diversos tipos de movimentos de substâncias fluidas, plásticas ou elásticas, respondendo a tensões moleculares e gravitacionais. MORGAN (1986), dentre outros, esclarece bem a íntima relação entre estes movimentos e os de escoamento pluvial-fluvial superficiais, e de fluxos internos-freáticos, achando difícil determinar a diferenciação entre eles, se forem considerados como um fenômeno erosivo contínuo e interativo na esculturação do relevo terrestre. FINLAYSON \& STATHAN (1980) acrescentam ainda que, no mecanismo desencadeador dos deslizamentos, o conjunto dos processos intempéricos é o que leva à instabilização da vertente a longo prazo. Enquanto isto, causas a curto prazo ocorrem quando o freático se torna mais alto pós chuvas pesadas na estação úmida, ocasionando pressão nos poros dos materiais, havendo então fortes relações entre a queda de material e tempo úmido chuvoso. As condições de umidade do solo são determinadas, segundo POESEN (1984), por suas propriedades, por declividade, influências estruturais e raízes da vegetação. A erosão basal e a sismicidade também são fatores a acarretar mudanças a curto prazo nos ângulos de declividade e a aumentar o grau de instabilidade da vertente. A diminuição da coesão interna dos materiais superficiais e a redução da resistência ao cizalhamento não alcançarão limiares para que os movimentos ocorram, se o ângulo de repouso dos materiais for igual ao dessa resistência. Com a umidade, porém, a água dos espaços entre os poros exerce pressão, reduz a fricção entre os grãos e a resistência ao cizalhamento, diminuindo a estabilidade dos mesmos; por conseqüência, os movimentos podem acontecer. Testes de "sheargraph" têm sido utilizados no estudo de tais problemas (DE PLOEY \& CRUZ, 1979; DE PLOEY et al., 1978).
A ocorrência de um episódio pluvial em 17 e 18 de março de 1967 nas escarpas costeiras do município de Caraguatatuba (CRUZ, 1974; FULFARO et al., 1976; AB'SABER, 1985, dentre outros) e a ação de extensos e intensos processos de movimentos de massa causaram um grande impacto ambiental, numa frente marítima de mais ou menos $40 \mathrm{~km}$ de escarpas costeiras, mais concentrados em uma área de aproximadamente $180 \mathrm{~km}^{2}$ em torno da cidade de Caraguatatuba. Foi antecedido por um verão muito chuvoso, propiciando alimentação dos lençóis freáticos e encharcamento progressivo dos materiais coluviais e de alteração.

Além das escarpas da serra nos arredores de Caraguatatuba, a bacia do rio Santo Antônio drena a face leste do pico do Tinga, a $685 \mathrm{~m}$ de altitude, e as faces oeste dos diversos morros que rodeiam o vale, em boa parte já separados das vertentes da serra, a partir do falhamento Bertioga-Caraguatatuba ou dos Quinhentos Reis, em esporões ou em morros testemunhos. Funcionam como dispersores de águas, as quais se organizam em uma rede densa de canais pluviais, nas vertentes, e fluviais, nos fundos de vale, seguindo direções estruturais. Na época, esta rede determinou a distribuição dos escorregamentos em prancha, alongados e estreitos, ou mais curtos e largos, em leque, de acordo com o comprimento das vertentes atingidas e a amplitude topográfica de seus vales. Todas as faces do pico do Tinga, com declividades predominantes acima de $22 \%$, apresentaram-se como uma das áreas mais propícias para o desenvolvimento de escorregamentos alongados e estreitos; áreas de amplitude de mais de $600 \mathrm{~m}$ concentraram deslizamentos em canais pluviofluviais numa extensão aproximada de 200-250m. Na sua face sudeste, em esporão secundário rebaixado, correspondente à linha de falha Caraguatatuba-Camburu, ocorreram curtos e largos em amplitudes de $150-200 \mathrm{~m}$ e extensões de $25 \mathrm{~m}$, desnudando flancos rochosos em cicatrizes de mais de $50 \mathrm{~m}$ de largura.

Nascendo entre $800-850 \mathrm{~m}$ de altitude no reverso e nos topos das escarpas a nor-nordeste (fig. 1) e desaguando no Santo Antônio perto da sede do Parque Florestal, o ribeirão afluente da margem esquerda do Santo Antônio é um dos bons exemplos de organização da rede de escorregamentos em total acordo com a rede fluvial. Em amplitudes topográficas de $800-900 \mathrm{~m}$, transportou na época, por quase $1 \mathrm{~km}$, materiais com blocos de até $5 \mathrm{~m}$ de diâmetro maior misturados a troncos, galhos e lama, para ajudar a entulhar o pequeno alvéolo de montante e recobrir a planície do grande alvéolo a jusante e a do baixo Santo Antônio até o mar. Os córregos Manteigueira e do Ouro contribuíram muito menos pa- 
ra esse entulhamento; seus altos vales ficaram, em grande parte, como também boa parte do grande anfiteatro a nor-noroeste, a salvo dos fenômenos de deslizamento. Pressupomos ser essa menor exposição aos fluxos pluviais do episódio chuvoso devida à proteção oferecida pelo pico do Tinga e à profundidade dos dois vales embutidos no grande anfiteatro, em amplitudes de $750-800 \mathrm{~m}$. Dever-se-ia considerar ainda a influência das variações do material de alteração, de acordo com as variações litológicas das rochas granitóides e migmatitos.

Nas altas vertentes dos morros do Pau d'Alho e da Divisa (fig. 3), as cicatrizes são bem visíveis, assinalando o início dos escorregamentos. É também nítido o ajustamento da rede pluviofluvial e dos escorregamentos aos alinhamentos estruturais, nas escarpas drenadas pelas bacias dos rios Camburu e do Pau d'Alho. Neste setor, em amplitudes de $700-800 \mathrm{~m}$, os deslizamentos alcançaram, por vezes, extensões de 3 a $3,5 \mathrm{~km}$ até entulhar as pequenas planícies al- veolares e, após, atingir a grande planície fluviomarinha da baixada de Caraguatatuba e o mar. Nem todos os produtos dos deslocamentos e deslizamentos dos materiais coluviais e de alteração descem às planícies; podem ficar retidos em depressões nas vertentes, em patamares, em rampas de declives mais amenos, ou formar barreiras em estreitamentos ao longo dos talvegues, sobre soleiras rochosas.

Uma carta de declividades confeccionada anteriormente em área de amostragem de $30 \mathrm{~km} 2$, no vale do Santo Antônio (CRUZ, 1974), mostrou a predominância de declividades superiores a $40 \%$ (22.) em $16,29 \mathrm{~km} 2$, ou seja, em $54,3 \%$ da área considerada. Posterior levantamento e mapeamento das cicatrizes de escorregamentos (CRUZ, 1975) existentes na mesma área, efetuado a partir do recobrimento aerofotogramétrico de 1973 da VASP, permitiu constatar que as vertentes escarpadas com mais de $22^{\circ}$. foram as preferencialmente atingidas, como demonstra a tabela:

\begin{tabular}{|c|c|c|c|c|}
\hline \multicolumn{2}{|c|}{$\begin{array}{l}\text { CLASSES DE DECLIVIDADE } \\
\text { Valores em }\end{array}$} & \multicolumn{3}{|c|}{$\begin{array}{c}\text { Superfície dos } \\
\text { Escorregamentos em Relação } \\
\text { ao Total da Bacia }\end{array}$} \\
\hline$\%$ & Graus & $\mathrm{Km}^{2}$ & e & $\%$ \\
\hline 40 & $22^{\circ}$ & 3,5800 & & 11,93 \\
\hline 30 a 40 & 17 a $22^{\circ}$ & 0,3031 & & 1,10 \\
\hline 20 a 30 & 12 a $17^{\circ}$ & 0,2996 & & 0,99 \\
\hline 10 a 20 & 6 a $12^{\circ}$ & 0,0432 & & 0,14 \\
\hline 5 a 10 & 3 a $6^{0}$ & 0,0242 & & 0,08 \\
\hline 5 & $3^{\circ}$ & 0,0086 & & 0,02 \\
\hline TOTAL & & $4,2587 \mathrm{~km}^{2}$ & & $14,26 \%$ \\
\hline
\end{tabular}

Fonte: CRUZ, 1975

Isto significa que, em $14,26 \%$ da área da bacia do Santo Antônio atingida por escorregamentos, $11,93 \%$ ocorreram em vertentes com declividades acima de $22^{\circ}$.

Foi importante verificar a ocorrência de duas áreas principais de grande concentração de deslizamentos, em função de sua situação topomorfológica, cruzamento de alinhamentos estruturais e posição geográfica. Isto nos deu a oportunidade de calcular as isopletas, ou seja, curvas de igual valor da densidade das cicatrizes, a partir das fotografias aéreas (figs. 2 e 4). A evolução geomorfológica de vertentes escarpadas pode sẹr estudada a partir da determinação do seu estadó de estabilidade. Um dos meios para isto é o inventário da posição e concentração dos deslizamentos nelas ocorridos. A confecção de um mapa de isopletas em área de expressão amostral fornece, ao indicar pontos e áreas instáveis, informações a respeito dessa distribuição. $\mathrm{O}$ traçado das isopletas (figs. 2 e 4 ) inspirou-se nos trabalhos de autores como SCHMID \& MACCANNEL (1955), CAMPBELL (1973), BRABB \& PAMPEYAN (1972), WRIGHT \& NILSEN (1974), WRIGHT et al. (1974). Um círculo de $22,7 \mathrm{~mm}$ de raio, desenhado em papel transparente, foi dividido em quadrados de $4 \mathrm{~mm}^{2}$ de área, o que corresponde ao total aproximado de 400 quadrados no círculo. Desta forma, cada conjunto de 4 quadrados corresponde a $1 \%$ da área do círculo. A área amostral na carta topográfica-base foi também dividida em uma rede de quadrados de $2 \mathrm{~cm}$ de lado, aproveitando as coordenadas existentes, de tal modo que quatro quadrados correspondessem aproximadamente à área do círculo. Fez-se coincidir o centro do círculo com os cruzamentos do quadriculado da carta e foram quantificados os 


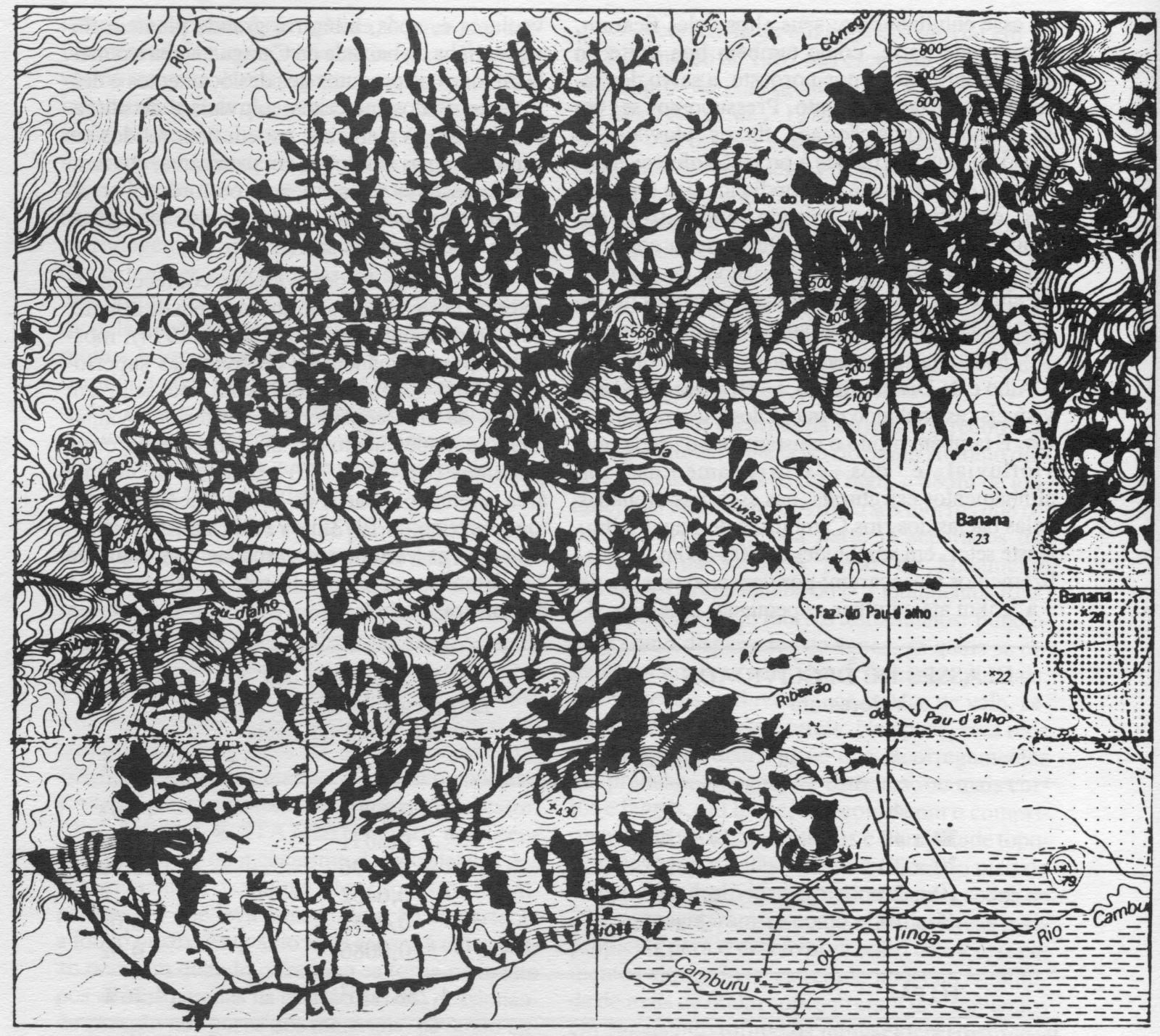

Equidistancia das Curvas do Nivel: $20 \mathrm{~m}$

FONTE : Folhe Topografica Coraguafafuba-Estedo de Sao Paclo

Escole : 1:50.000-186E - 1972 


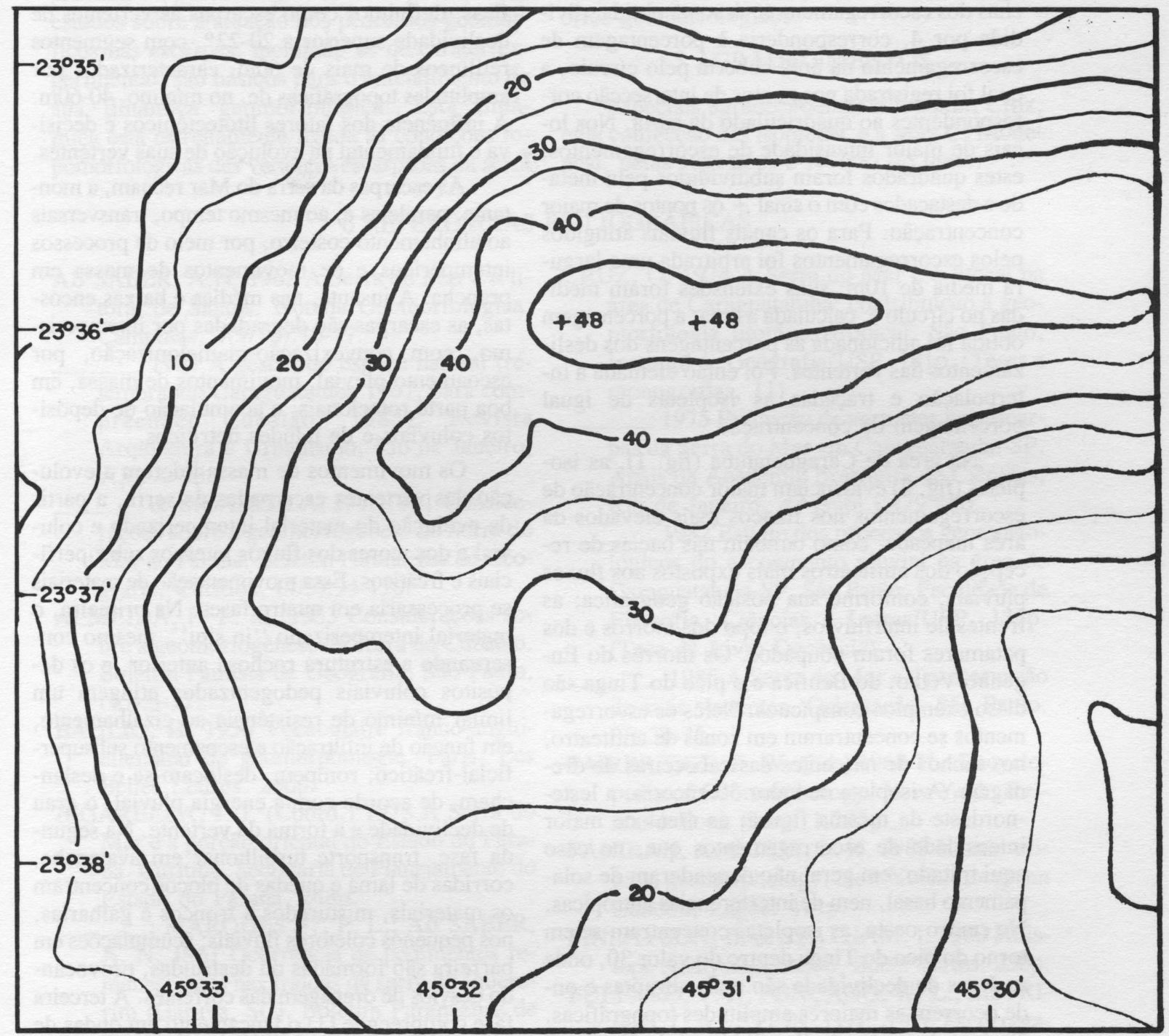

Fig. 4

Equidistancia das Isopletas: valor 5 
quadrados do círculo correspondentes às manchas dos escorregamentos. A soma obtida, dividida por 4 , corresponderia à porcentagem de escorregamento na área coberta pelo círculo, a qual foi registrada nos pontos de intersecção correspondentes ao quadriculado da carta. Nos locais de maior intensidade de escorregamentos, estes quadrados foram subdivididos pela metade e destacados com o sinal + os pontos de maior concentração. Para os canais fluviais atingidos pelos escorregamentos foi arbitrada uma largura média de $10 \mathrm{~m}$; suas extensões foram medidas no círculo e, calculada a área, a porcentagem obtida foi adicionada às porcentagens dos deslizamentos das vertentes. Foi então efetuada a interpolação e traçadas as isopletas de igual porcentagem de concentração.

$\mathrm{Na}$ área de Caraguatatuba (fig. 1), as isopletas (fig. 2) evidenciam maior concentração de escorregamentos nos flancos mais elevados da área mapeada, como também nas bacias de recepção dos anfiteatros mais expostos aos fluxos pluviais, conforme sua posição geográfica; as frentes de interflúvios, o topo dos morros e dos patamares foram poupados. Os morros do Engenho Velho, do Benfica e o pico do Tinga são disso exemplos conspícuos. Neles os escorregamentos se concentraram em zonas de anfiteatro, nos nichos de nascentes das cabeceiras de drenagem. A isopleta de valor 30 encerra, a leste-nordeste da mesma figura, as áreas de maior intensidade de escorregamentos que, no caso aqui tratado, em geral não dependeram de solapamento basal, nem de interferências antrópicas. No centro-oeste, as isopletas concentram-se em torno do pico do Tinga dentro do valor 30 , onde as áreas de declividade são mais abruptas e onde ocorrem as maiores amplitudes topográficas. $\mathrm{Na}$ área dos vales do Pau d'Alho e do Camburu (figs. 3 e 4), as isopletas mais relacionadas à serra possuem uma forma alongada de oeste para leste, concentrando-se mais nas escarpas de direção leste. Apresentam duas áreas de concentração: uma ligada às altas vertentes dos morros da Divisa e do Pau d'Alho, outra à disposição das escarpas e à mudança de direção, influenciada pela falha do ribeirão do Ouro e outros lineamentos paralelos e transversais às escarpas. Chama a atenção a perfeita ordenação arborescente dos escorregamentos, estritamente relacionados ao traçado das linhas estruturais e da drenagem. As isopletas dispõem-se paralelamente à direção geral da frente do escarpamento.

\section{CONSIDERAÇÕES FINAIS}

Um conjunto de escarpas ou vertentes escarpadas constitui um escarpamento ou um alinhamento de escarpas. De acordo com nossas observações, experiências e consultas bibliográficas, definimos como escarpas as vertentes de declividade superior a $20-22^{\circ}$, com segmentos retilíneos de mais de $60 \mathrm{~m}$, caracterizados por amplitudes topográficas de, no mínimo, $40-60 \mathrm{~m}$. A influência dos fatores litotectônicos é decisiva e fundamental na evolução de suas vertentes.

As escarpas da serra do Mar recuam, a montante, paralelas e, ao mesmo tempo, transversais ao alinhamento costeiro, por meio de processos intempéricos e de movimentos de massa em prancha. A jusante, nas médias e baixas encostas, as escarpas são degradadas por intemperismo, com convexização-mamelonização, por escoamento pluvial, movimentos de massa, em boa parte rotacionais, e acumulação de depósitos coluviais e de taludes detríticos.

Os movimentos de massa lideram a evolução das vertentes escarpadas da serra, a partir da evolução do material intemperizado e coluvial e dos teores dos fluxos internos subsuperficiais e freáticos. Essa movimentação de materiais se processaria em quatro fases. Na primeira, o material intemperizado "in situ", mesmo conservando a estrutura rochosa anterior, e os depósitos coluviais pedogenizados atingem um limiar mínimo de resistência ao cizalhamento, em função de infiltração e escoamento subsuperficial-freático; rompem, deslocam-se e deslancham, de acordo com a energia pluvial, o grau de declividade e a forma da vertente. Na segunda fase, transporte turbilhonar em avalanche, corridas de lama e quedas de blocos concentram os materiais, misturados a troncos e galharias, nos pequenos coletores fluviais; acumulações em barreira são formadas ou destruídas, provocando desvios de drenagem das correntes. A terceira fase compreende (1) o lançamento em ondas de todos os materiais, por avalanche e corridas de lama, nos canais fluviais maiores, então alargados, (2) a passagem pelas rampas de desgaste e (3) a sua chegada ao sopé das escarpas, onde ocorre entulhamento dos pequenos alvéolos e formação/destruição de taludes detríticos. $\mathrm{Na}$ quarta fase, já sem os blocos e outros detritos maiores e mais pesados, o escoamento ainda turbilhonar, mas também laminar, espraia e anastomosa as correntes de lama nas planícies, até o mar.

A alta sensibilidade erosiva das escarpas da serra, principalmente por ocasião de eventos naturais esporádicos e de grande magnitude, exige cuidados permanentes para sua preservação. A manutenção de uma estabilidade mínima dos materiais superficiais e mantos florestais, com suas formações herbáceas e respectiva serrapilheira, é fundamental. Qualquer tipo de atividade humana tenderá a alterar essa estabilidade 
precária e a provocar graves conseqüências. Os estudos sobre a atuação dos processos geomórficos nas escarpas, incluindo os de caráter experimental, são básicos para o entendimento de sua dinâmica geomorfológica. Esta dinâmica está estreitamente ligada às condições topomorfológicas das vertentes escarpadas da serra do Mar, especialmente propícias aos desequilíbrios geomorfológicos.

\section{AGRADECIMENTOS}

Especiais agradecimentos a Joaquim Cruz, pela confecção das isopletas, e a May C. Modenesi, pelas sugestões e revisão do texto.

\section{REFERÊNCIAS BIBLIOGRÁFICAS}

AB'SABER, A.N. 1962 A Serra do Mar e o litoral de Santos. Notícia Geomorfológica, Campinas, 5(9/10):70-77.

1985 A gestão do espaço natural (relembrando Caraguatatuba 1967, para compreender Cubatão, 1985). Revista Arquitetura e Urbanismo, Rio de Janeiro, 1(3):90-93.

\& BIGARELLA, J. J. 1961 Considerações sobre a geomorfogênese da Serra do Mar no Paraná. Boletim Paranaense de Geografia, Curitiba, (4/5):94-110.

ALMEIDA, F. F. M. 1953 Considerações sobre a geomorfogênese da Serra do Cubatão. Boletim Paulista de Geografia, São Paulo, (15):3-17.

BAULIG, H. 1956 Vocabulaire franco-angloallemand de géomorphologie. Paris, Les Belles Lettres. 230p.

BIGARELLA, J. J. (Coord.) 1978 A Serra do Mar e a porção oriental do Estado do Paraná. Curitiba, Secretaria de Planejamento do Estado do Paraná, 248p.

; MARQUES Fo, P. L.; AB'SABER, A. N. 1961 Ocorrência de pedimentos remanescentes nas fraldas da serra do Iquererim (Garuva, SC). Boletim Paranaense de Geografia, Curitiba, (4/5):82-93.

BIROT, P. 1955 Les méthodes de la morphologie. Paris, P. U. F. 177p.

BRABB, E E. \& PAMPEYAN, E. H. 1972 Preliminary map of landslide deposits in San Mateo Country, California. Washington, D. C., United States Geological Survey/Department of Housing and Urban Development. (Miscellaneous Field Studies, Map-344)

CAMPBELL, R. N. 1973 Isopleth map of landslide deposits, Point Dume Quadrangle, Los Angeles Country, California; and experiment in generalizing and quantifying areal distribution of landslides. Washington, D. C., United States Geological Survey/Department of the country Engineer. (Miscellaneous Field Studies Map MF-535)

CHORLEY, R. J.; SCHUMM, S. A.; SUDGEN, D. E. 1984 Geomorphology. London, Methuen. 605p.
CRUZ, O. 1974 A Serra do Mar e o litoral na área de Caraguatatuba: contribuição à geomorfologia litorânea tropical. São Paulo, Instituto de Geografia/USP. 181p. (Teses e monografias, 11)

1975 Evolução de vertentes nas escarpas da Serra do Mar em Caraguatatuba-SP. Anais da Academia Brasileira de Ciências, Rio de Janeiro, 47 (supl.):479-480.

1982 Estudo dos processos geomorfológicos do escoamento pluvial na área de Caraguatatuba-SP. São Paulo, Faculdade de Filosofia, Ciências e Letras/USP. 135p. (Tese de Livre-Docência)

1986 A Serra do Mar e a preservação de suas vertentes. Orientação, São Paulo. (7):39-75.

FAIRBRIDGE, R. W. (Ed.) 1968 The Encyclopedia of Geomorphology. New York, Reinhold Book Corp. 1.295p.

FANIRAN, A. \& JEJE, L. K. 1983 Humid tropical geomorphology. New York, Longman London, Lagos. 414p.

FINLAYSON, B. \& STATHAM, I. 1980 Hillslope Analysis. London, Butterworths. 230p.

FÚLFARO, V. J.; PONÇANO, W. L.; BISTRICHI, C.A.; STEIN, D. P. 1976 Escorregamento de Caraguatatuba: expressão atual e registro na coluna sedimentar da planície costeira adjacente. IN: CONGRESSO BRASILEIRO DE GEOLOGIA DE ENGENHARIA, 1․, Rio de Janeiro, 1976. Anais. Rio de Janeiro, Associação Brasileira de Geologia de Engenharia. v. 2. p.341-346. HASUI, Y. (Coord.) 1982 Mapa geológico da folha Caraguatatuba (SF-23-Y-D-VI-1). São Paulo, CPRM/PRÓ-MINÉRIO. Esc. 1:50.000.

IPT - INSTITUTO DE PESQUISAS TECNOLÓGICAS 1977 Mapa geológico da Região Administrativa 3 (Vale do Paraíba) e parte da Região Administrativa 2 (Litoral) do Estado de São Paulo. Esc. 1:200.000. (Publicação IPT, 1106)

1981 Mapa geológico do Estado de São Paulo. São Paulo, IPT/PRÓ-MINÉRIO. Esc. 1:500.000. 
KING, C. A. M. (Ed.) 1976 Landforms and geomorphology: concepts and history. Dowden, Hutchinson \& Rossa Inc. 404p.

KING, L. C. 1962 The Morphology of the Earth. London, Oliver \& Boyd. 726p.

LOCZY, L. \& LADEIRA, E. A. 1981 Geologia estrutural e introdução à geotectônica. São Paulo, Edhgard Blücher Ltda. 528p.

MORGAN, R. P. C. 1986 Soil erosion and conservation. London, Longman. 298p.

PENCK, W. 1953 Morphological analysis of landforms. IN: CZECH, H \& BOSWELL, K. C. Die morphologische analyse. London, McMillan.

DE PLOEY, Y. \& CRUZ, O. 1979 Landslides in the serra do Mar, Brazil. Catena, Berlin, 6(2):111-122.

$$
\text { ; ; MODENESI, M. C. } 1978
$$

Résistances au cisaillement et conditions de glissements de terrain à Caraguatatuba et à Campos do Jordão, Estado de São Paulo. IN: COLÓQUIO INTERDISCIPLINAR FRANCO-BRASILEIRO SOBRE ESTUDO E CARTOGRAFIA DE FORMAÇÕES SUPERFICIAIS E SUAS APLICAÇÕES EM REGIÕES TROPICAIS. Comunicação e Debate. São Paulo, Instituto de Geografia/USP. v. 1 p. $393-402$.

POESEN, J. 1984 The influence of slope angle in infiltration rate and hortonian overland flow volume. Zeitschrift für Geomorphologie, Berlin, 49:117-131 (suppl.)

QUINN, J. H. 1968 Escarpment, scarp. IN: FAIRBRIDGE, R. W. (ed.). The Encyclopedia of Geomorphology. New York, Reinhold Book Corp. 1.295p.
RUHE, R. V. 1975 Geomorphology. New York, Houghton Mifflin Co. 245p.

SCHMID, C. J. \& McCANNEL, E. H. 1955 Basic problems, tecniques and theory of isopleth maping. American Statistical Association Journal, Washington, D.C., 50(269):220-239.

SCHUMM, S. A. \& CHORLEY, R. J. 1966 Talus weathering and scarps recession in the Colorado plateau. Zeitschrift für Geomorphologie, Berlin, 10(1):11-36.

SHARPE, C. F. S. 1938 Landslides and related phenomena. New York, Columbia University Press. 120 p.

SWAN, S. B. St. C. 1972 Landsurface evolution and related problems with reference to a humid tropical region: Yohor, Malaya. Zeitschrift für Geomorphologie, Berlin, 16(2):160-181.

WRIGHT, R. H. \& NILSEN, T. H. 1974 Isoplet maps of landslide deposits, southern San Francisco Bay region, California. United States Geological Survey. (Miscellaneous Field Studies Map MF-550). Scale $1: 125.000$.

; CAMPBELL, R. N.; NILSEN, T. H. 1974 Preparation and use of isopleth maps of landslide deposits. Geology, Boulder, Co., 2(10):483-485.

YOUNG, A. 1972 Slopes. London, Oliver \& Boyd. 288p.

ZARUBA, Q. \& MENCL, V. 1969 Landslides and their control. Amsterdam, Elsevier Academia. 214p.

Manuscrito recebido em novembro de 89 